\title{
Insulin therapy in pancreas donors as a predictor of subsequent transplant outcome
}

Link to publication record in Manchester Research Explorer

\section{Citation for published version (APA):}

Shapey, I., Summers, A., Khambalia, H., Augustine, T., Rutter, M., \& Van Dellen, D. (2017). Insulin therapy in pancreas donors as a predictor of subsequent transplant outcome. Poster session presented at British Transplantation Society Annual Congress, Harrogate, United Kingdom.

\section{Citing this paper}

Please note that where the full-text provided on Manchester Research Explorer is the Author Accepted Manuscript or Proof version this may differ from the final Published version. If citing, it is advised that you check and use the publisher's definitive version.

\section{General rights}

Copyright and moral rights for the publications made accessible in the Research Explorer are retained by the authors and/or other copyright owners and it is a condition of accessing publications that users recognise and abide by the legal requirements associated with these rights.

\section{Takedown policy}

If you believe that this document breaches copyright please refer to the University of Manchester's Takedown Procedures [http://man.ac.uk/04Y6Bo] or contact uml.scholarlycommunications@manchester.ac.uk providing relevant details, so we can investigate your claim.

\section{OPEN ACCESS}




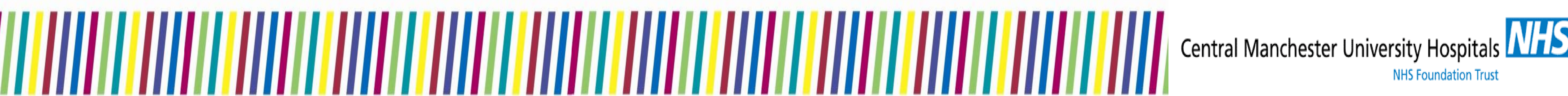 Insulin therapy in pancreas donors as a predictor of subsequent transplant outcome
}

\author{
IM Shapey, A Summers, H Khambalia, T Augustine, MK Rutter, D van Dellen \\ Department of Renal and Pancreatic Transplantation, Manchester Royal Infirmary \\ Manchester, United Kingdom
}

\section{Introduction}

- Brain stem death causes high levels of systemic catecholamines and inflammation affecting all organs.

- Hyperglycaemia following brain death is common and is managed with insulin in about half of all donors.

Aim

- We hypothesised that donor insulin use (DIU) is a marker of irreversible pancreatic beta-cell death.

- We aimed to assess relationships of DIU to pancreas transplant outcome and function.

\section{Methods}

- National data from the UK Transplant registry (2004-2016) was reviewed retrospectively to determine donor variables associated with DIU and its relationship with graft survival.

- Early non-technical graft failure (transplant pancreatitis) was assessed from histology reports using our regional data.

- In a sub-group, we determined relationships between DIU and early c-peptide secretion.

\section{Results}

Table 1: Donor variables associated with insulin use in intensive care

\begin{tabular}{lrrr} 
& \multicolumn{2}{c}{$\begin{array}{c}\text { Donor insulin use in intensive care } \\
\text { Yes }(\mathbf{n}=1005)\end{array}$} & $\begin{array}{c}\text { p-value } \\
\text { (univariate) }\end{array}$ \\
Donor variables & & & \\
Age & & & \\
Sex (male) & $35.65(\mathrm{SD} 13.14)$ & $34.17(\mathrm{SD} 13.85)$ & 0.016 \\
Ethnicity & $460(45.8 \%)$ & $507(54.1 \%)$ & $<0.0001$ \\
$\quad$ White & & & \\
$\quad$ Asian & $917(93.5 \%)$ & $875(95.2 \%)$ & 0.126 \\
Black & $24(2.4 \%)$ & $14(1.5 \%)$ & 0.151 \\
$\quad$ Other & $16(1.6 \%)$ & $11(1.2 \%)$ & 0.577 \\
BMl & $24(2.4 \%)$ & $19(2.1 \%)$ & 0.161 \\
Smoking (Y/N) & $23.49(\mathrm{SD} 3.58)$ & $23.77(\mathrm{SD} 3.57)$ & 0.085 \\
Alcohol (Y/N) & $496(50.1 \%)$ & $479(52.1 \%)$ & 0.391 \\
Hypertension (Y/N) & $69(7.2 \%)$ & $83(9.3 \%)$ & 0.088 \\
Cardiac disease (Y/N) & $74(7.5 \%)$ & $89(9.7 \%)$ & 0.083 \\
Cardiac arrest (Y/N) & $34(3.5 \%)$ & $26(2.9 \%)$ & 0.474 \\
Creatinine & $275(28.2 \%)$ & $299(33.4 \%)$ & 0.015 \\
Peri-retrieval hypotension & $61.29(\mathrm{SD} 47.8)$ & $82.04(\mathrm{SD} 51.87)$ & 0.78 \\
Donor Type (DBD) & $660(67.0 \%)$ & $542(61.0 \%)$ & 0.004 \\
Cause of death & $909(90.4 \%)$ & $699(74.5 \%)$ & $<0.0001$ \\
$\quad$ Trauma & & & \\
$\quad$ Meningitis & $140(13.9 \%)$ & $180(19.2 \%)$ & 0.002 \\
Stroke (thrombo-embolic) & $35(3.5 \%)$ & $11(11.7 \%)$ & 0.0001 \\
Intracranial haemorrhage & $62(6.2 \%)$ & $47(5.0 \%)$ & 0.2579 \\
Hypoxic brain damage & $516(51.3 \%)$ & $454(48.4 \%)$ & 0.1669 \\
Brain tumour & $173(17.2 \%)$ & $195(20.8 \%)$ & 0.0049 \\
Other & $14(13.9 \%)$ & $14(1.5 \%)$ & 0.86249 \\
& $58(57.7 \%)$ & $34(3.6 \%)$ & 0.0025
\end{tabular}

\section{Conclusions}

Figure 1: Donor-recipient variable adjusted survival plot according to donor insulin use or non-use

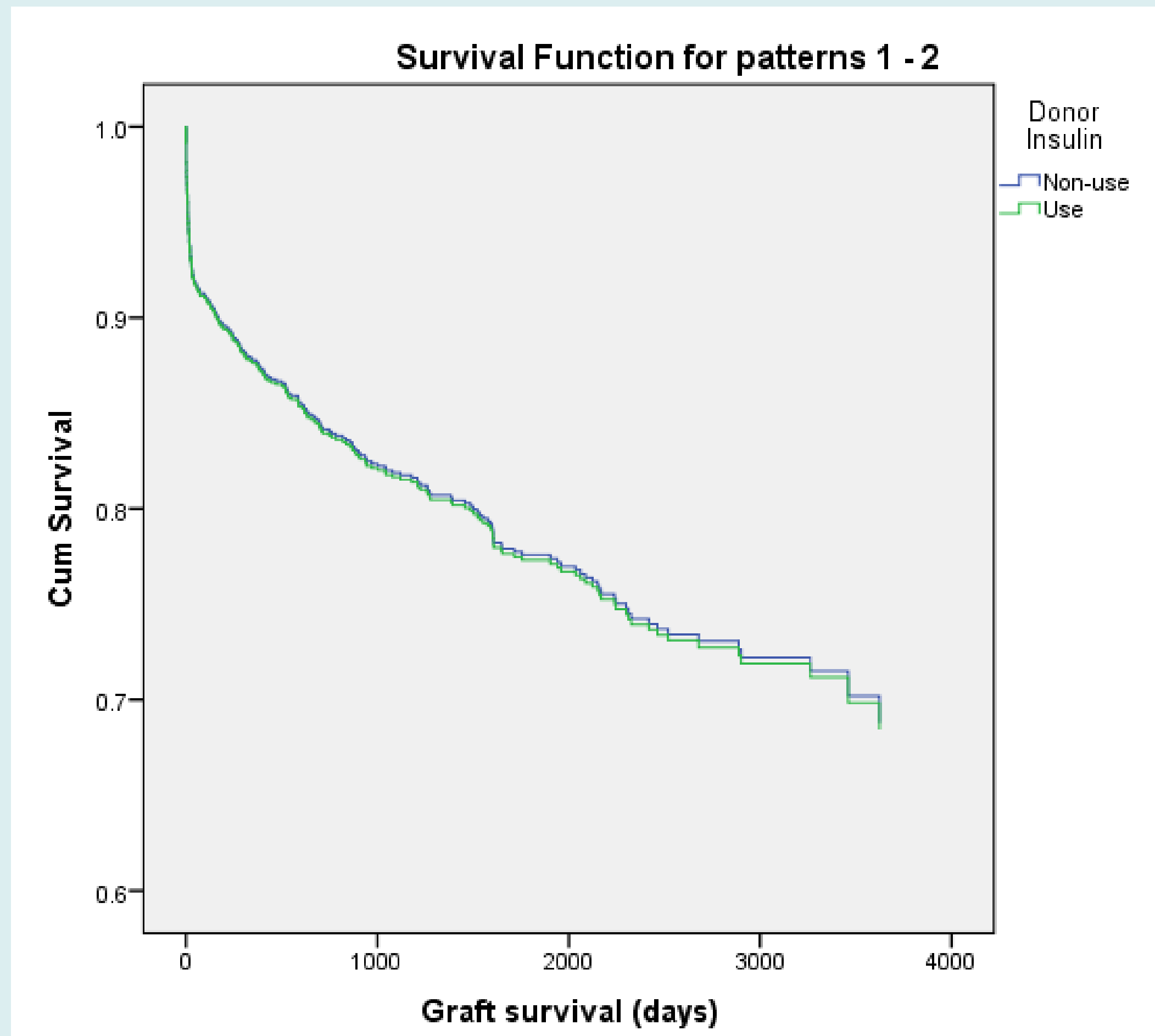

Insulin vs. non-insulin use (Cox Regression)

There was no difference in graft survival (median follow-up: 3 years) by DIU:

- donor variable-adjusted HR (95\%Cl), : 0.93 (0.76-1.14), $\mathrm{p}=0.684$

- donor and recipient variable-adjusted HR 1.0, (0.77-1.29), $p=0.978$

Figure 2 - Early non-technical Figure 3 - c-peptide at 72 graft loss according to donor hours post-transplant insulin use according to donor insulin use

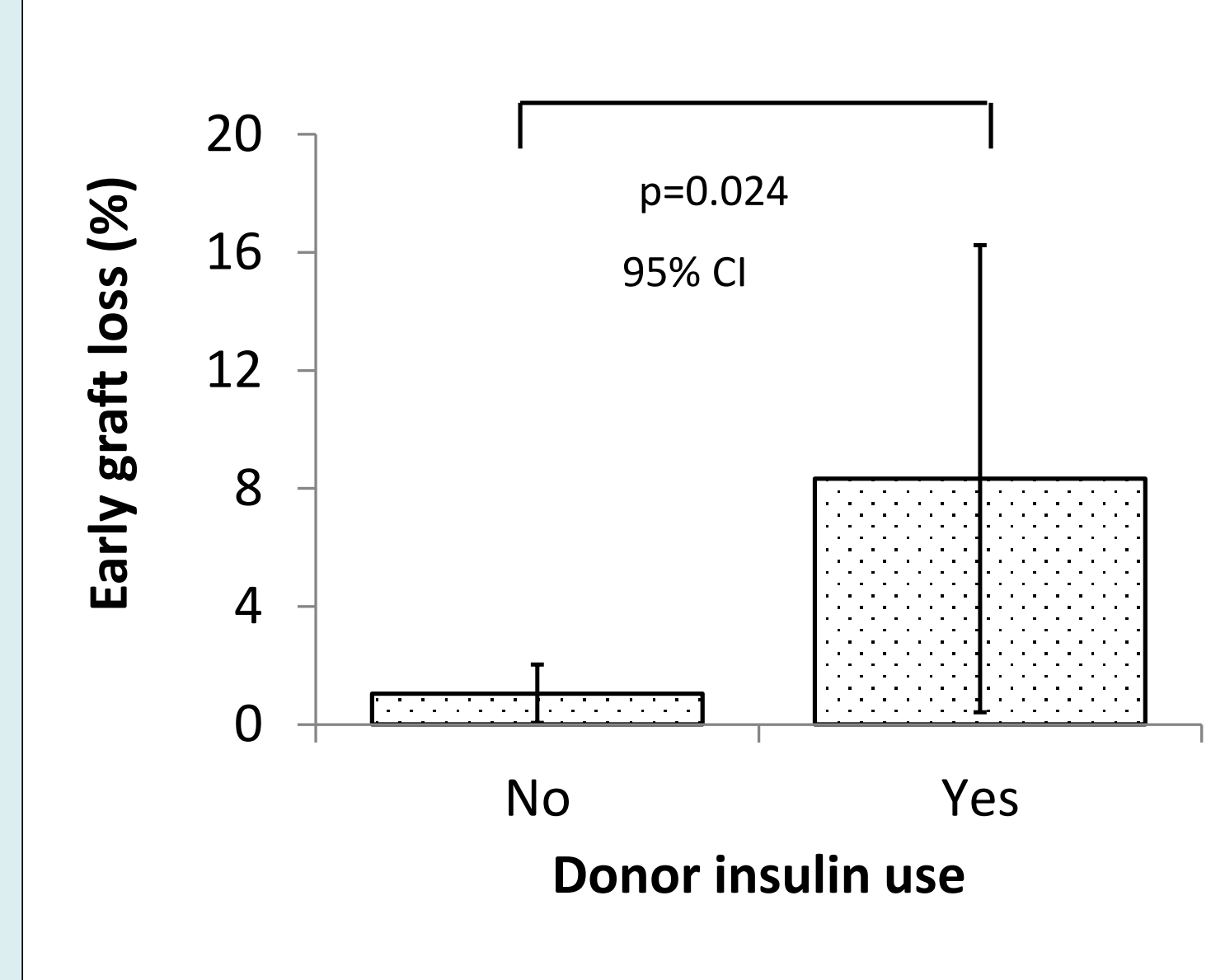

Proportion failing: with vs. without insulin: 6/72 (8.3\%) vs $1 / 96(1 \%)$ $p=0.024$ ).

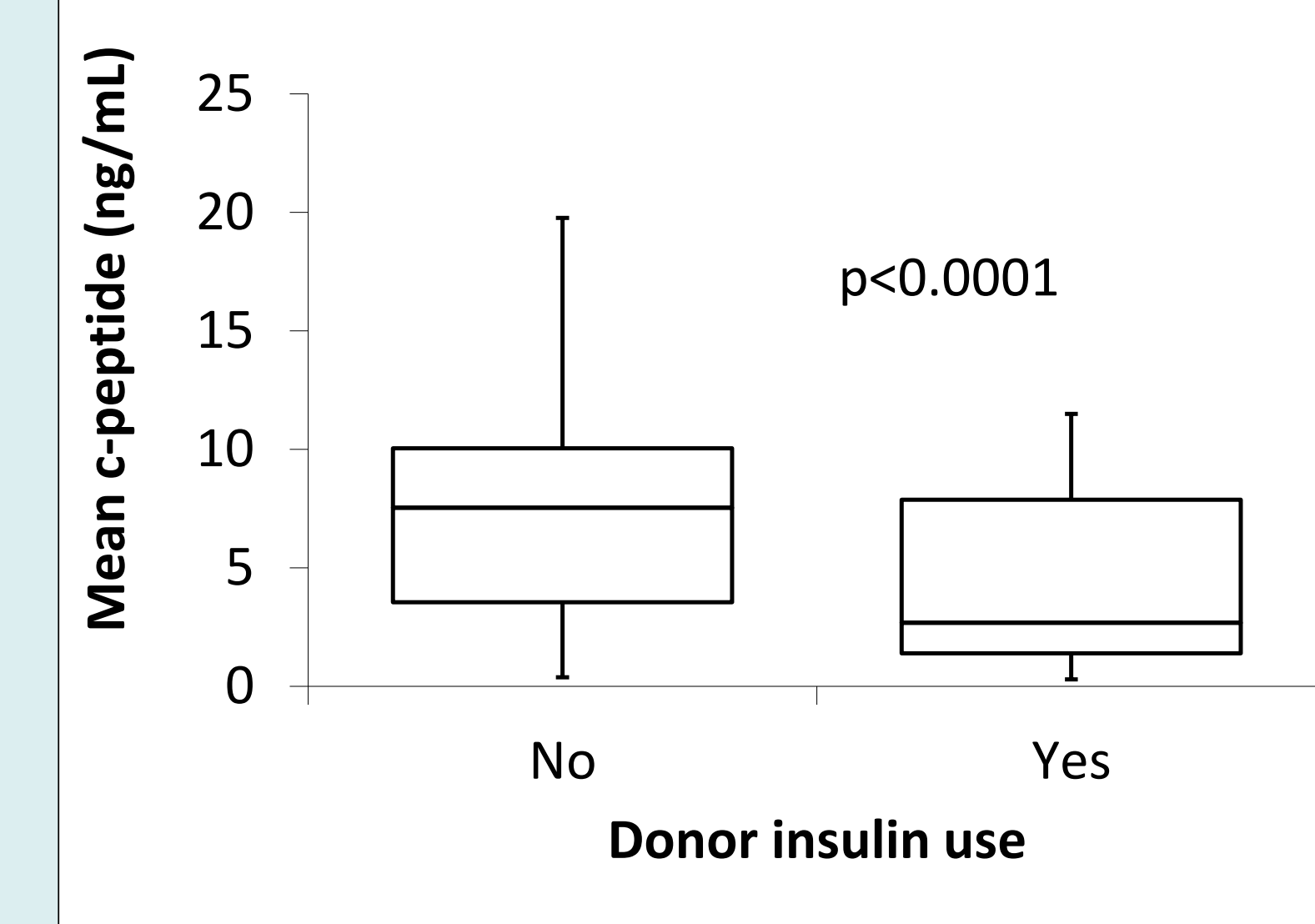

In a sub-group $(\mathrm{n}=46)$, C-peptide levels in insulin $v s$ no insulin donors: 4.3 vs. $7.5 \mathrm{ng} / \mathrm{mL}, p<0.001$ ).

- DIU could be a useful clinical predictor of early pancreas graft outcome and function.

- Further understanding of the physiological processes causing hyperglycaemia in donors could improve donor selection and lead to better outcomes. 